\title{
Anaplastic Oligoastrocytoma, Not Otherwise Specified
}

National Cancer Institute

\section{Source}

National Cancer Institute. Anaplastic Oligoastrocytoma, Not Otherwise Specified. NCI Thesaurus. Code C129324.

A diffuse anaplastic glioma characterized by the presence of both an astrocytic and an oligodendrog lial component and the absence of information on the IDH genes status. 